\title{
Electrophysiological Assessment, Causes and Management of Children with Supposed Hearing Loss in a Nigerian Ear Clinic
}

\author{
J. E. Tobih
}

Department of Otorhinolaryngology / Head \& Neck Surgery, Ladoke Akintola University of Technology Teaching Hospital, Osogbo, Nigeria

\section{A. Sogebi}

ENT Unit, Department of Surgery, OACHS, Olabisi Onabanjo University Sagamu, Ogun State, Nigeria

\section{A. A. Adeosun}

Department of Otorhinolaryngology, College of Medicine University of Ibadan, Oyo State, Nigeria

\section{A. 0. Olaosun}

Department of Otorhinolaryngology / Head \& Neck Surgery,

Ladoke Akintola University of Technology Teaching Hospital, Osogbo, Nigeria

\section{Odetoyinbo}

Department of Ear, Nose and Throat

Afe Babalola University Multi-System Hospital, Ado-Ekiti, Ekiti State, Nigeria

\section{T. O. Adedeji}

Department of Otorhinolaryngology / Head \& Neck Surgery, Ladoke Akintola University of Technology Teaching Hospital, Osogbo, Nigeria

\section{B. F. Ojurongbe}

Department of Otorhinolaryngology / Head \& Neck Surgery, Ladoke Akintola University of Technology Teaching Hospital, Osogbo, Nigeria

\section{B. A. Adegbosin}

Department of Otorhinolaryngology / Head \& Neck Surgery, Ladoke Akintola University of Technology Teaching Hospital, Osogbo, Nigeria

\section{Y. I. Adeyemo}

Department of Child Dental Health, Faculty of Dentistry

Bayero University Kano/Aminu Kano Teaching Hospital, Kano - Kano State, Nigeria

\section{Ogundiran (Corresponding Author)}

Department of Otorhinolaryngology / Head \& Neck Surgery, Ladoke Akintola University of Technology Teaching Hospital, Osogbo, Nigeria 
Tobih, J. E., Sogebi, O. A., Adeosun, A. A., Olaosun, A. O., Odetoyinbo, O., Adedeji, T. O., Ojurongbe, B. F., Adegbosin, B. A., Adeyemo, Y. I., \& Ogundiran, O. (2019). Electrophysiological Assessment, Causes and Management of Children With Supposed Hearing Loss in a Nigerian Ear Clinic. Advances in Social Sciences Research Journal, 6(9) 213-223.

\begin{abstract}
Background: Early detection and intervention programs for children with hearing loss have proven to be beneficial in developed countries, whereas in Nigeria, it takes an average of 1 to 5 years to identify hearing loss in children. Objective: The aim of this study is to objectively assess children with supposed hearing loss as seen in the otological clinic of LAUTECH Teaching Hospital, Osogbo, Nigeria. Methods: A retrospective study of 52 Children who presented at the otological clinic of LAUTECH Teaching Hospital with supposed hearing loss. Otoacoustic Emissions (MAICO ERO SCAN) and Auditory Brainstem Response (MAICO MB 11) were used to assess their hearing abilities. Analysis of data was done through simple percentage using SPSS 16. Results: OAE results revealed that only $7(13.5 \%)$ passed bilaterally while the remaining $45(86.5 \%)$ were referred. ABR reports revealed on the right ears that 6 $(11.5 \%)$ patients had normal hearing while the remaining $46(88.5 \%)$ were abnormal and on the left ears, $4(7.7 \%)$ patients were normal while $48(92.3 \%)$ were abnormal. Out of the 52 patients seen, $49(94.2 \%)$ accounted for and they received the best management that could be offered while the remaining $3(5.8 \%)$ were lost to follow up. Conclusion: In developing countries like ours, early screening of neonates is hampered by lack of appropriate equipment and appropriate national policy, hence devastating consequences are recorded whereas in developed countries, newborn hearing screening programs enable early hearing loss detection and intervention which produce long-lasting beneficial effects in every aspect of life endeavor.
\end{abstract}

\title{
INTRODUCTION
}

Hearing loss is a relatively common disease in newborns. Three to five out of every 1,000 newborns suffer from some form of congenital bilateral hearing loss above 40 decibels (dB), and 1-2 out of every 1,000 newborn babies have severe hearing loss. Global estimates by the WHO indicate that there are 466 million people in the world with disabling hearing loss, this is over $5 \%$ of the world's population; 34 million of these are children, and it is projected that there will be nearly 630 million people with disabling hearing loss by 2030 which could further rise to over 900 million $[1,2]$

Disabling hearing loss is defined as hearing loss greater than 40 decibels (dB) in adults 15 years and older in the better hearing ear and hearing loss greater than $30 \mathrm{~dB}$ in children $0-14$ years of age in the better hearing ear [3]. Two thirds of people with hearing impairment worldwide live in developing countries [4], with 2000 infants with hearing impairment are born daily [5].

The severity of hearing impairment is classified as mild (26-40 dB hearing level (dB HL), moderate (41-60 dB HL), severe (61-80 dB HL), and profound (81 dB HL or greater) [6]. According to WHO, unaddressed hearing loss poses an annual global cost of 750 billion dollars. There are significant costs associated with the impacts of unaddressed hearing loss. These include costs to the health, education and employment sectors as well as the costs associated with lost productivity. Interventions to address hearing loss including prevention, screening and provision of some form of rehabilitation are cost effective [3].

Hearing impairment in children has both developmental and economic impacts. It causes significant delays in language development and academic achievement (4). These delays are apparent even with mild to moderate hearing impairment [7]. Without early intervention, poor academic performance of children with hearing impairment persists. In these children, hearing impairment may only be identified much later in their education [8]. Hearing impairment is also associated with lower employment levels during adulthood [9]. In 2000 in the United States, severe to profound hearing impairment was estimated to cost society $\$ 297000$ over the lifetime of an affected individual, mostly due to reduced work productivity [10]. Furthermore, in 2015 in South Africa, total average medical costs for a child for the first 5-years and 10-years 
post-cochlear implantation were $\$ 27000$ and $\$ 40000$, respectively [11]. Management outcomes are excellent in infants in whom hearing impairment is identified early and an intervention is initiated by 9 months of age. These infants develop language at a rate that has the potential to match that of their peers who have no hearing impairment [4].

The Joint Committee of Infant Hearing, the American Academy of Pediatrics, and the American Academy of Audiology have published guidelines that recommend early detection of and intervention for infants with hearing impairment $[1,12,13]$. The goal of "Early Hearing Detection and Intervention" is to maximize linguistic competence and literacy development for children who have hearing impairment so that they do not fall behind their hearing unimpaired peers in communication, cognition, reading, and social-emotional development [13].

In the developing countries, patients are not detected early enough, thus the outcome of management is less than ideal. Among the challenges of management of children with hearing loss in the developing countries is lack of basic equipment for diagnosis, profiling and characterization of the hearing loss.

This study aims to review the OAE and ABR profiles of all the children with hearing loss at the Audiology unit, Ear, Nose and Throat Department, LAUTECH Teaching Hospital, Osogbo - Osun State, Nigeria. Furthermore, it seeks to find out the degree of hearing loss among the children and discuss the different management options for them.

\section{MATERIALS AND METHODS}

This is a retrospective descriptive study of all the children who had physiological and electrophysiological hearing assessments done between October 2012 and October 2016. All patients were assessed through OAE and ABR in which some were sedated while some were done under natural sleep. The anaesthetist team of the hospital was called for conscious sedation at the Audiology Unit, hence, the procedures were always easy without time wasting. Some of the patients (below 2 years) were normally assessed under natural sleep when they fell asleep shortly after breastfeeding.

\section{Brief Description of Otoacoustic Emission (OAE)}

The primary purpose of otoacoustic emission is to determine the cochlea status which is, specifically hair cell function. Otoacoustic emission machine is a portable machine used to determine the presence or absence of cochlea function. The normal cochlea does not just receive sound; it also produces low-intensity sounds called otoacoustic emissions (OAEs). These sounds are produced specifically by the cochlea and mostly by the outer hair cells as they expand and contract.

\section{OAE Procedure}

Patients are not booked, except on the general ENT clinic appointment, so as we run the clinic, any child that needs an OAE investigation is taken to the Audiology room. Infants (newborn to 23 months) and in some occasions, preschoolers (2-4 years) are carried by their parents in a quiet room or sound proof room, children and adolescents (5-17 years) could sit independently on a chair in a quiet room for the test to be performed. The patient needs not to fast since he or she does not need sedation and the procedure can last between 2-5 minutes. However, uncooperative children may be re-scheduled in which they could be sedated in order for the test to be performed. 
Tobih, J. E., Sogebi, O. A., Adeosun, A. A., Olaosun, A. O., Odetoyinbo, O., Adedeji, T. O., Ojurongbe, B. F., Adegbosin, B. A., Adeyemo, Y. I., \& Ogundiran, O. (2019). Electrophysiological Assessment, Causes and Management of Children With Supposed Hearing Loss in a Nigerian Ear Clinic. Advances in Social Sciences Research Journal, 6(9) 213-223.

Otoacoustic Emission is a non-invasive test of hearing, done by inserting a probe with a soft flexible tip into the ear canal to obtain a seal. The probe also contains microphone and speaker. Sounds generated in the probe and responses that come back from the cochlea are recorded. There are different probes for different ages; the probes are calibrated differently because of the significant differences in the ear canal volume. Multiple responses are averaged. All OAEs are analyzed relative to noise floor; therefore, reduction of physiologic and acoustic ambient noise is critical for good recordings. Because no behavioral response is required, OAEs can be obtained even from patients who are comatose. For a quiet and cooperative patient, recordings usually require less than a few minutes per ear. For an uncooperative or patient with noisy breathing, recordings may take significantly longer or may be impossible to obtain, thus the patient has to be re-scheduled and if still uncooperative, some sedatives may be used.

Once the cochlea processes the sound, an electrical stimulus is sent to the brainstem. In addition, there is a second and separate sound that does not travel up the nerve, but comes back out into the ear canal. This "byproduct" is the otoacoustic emission. The emission is then recorded with the microphone probe and represented pictorially on a liquid crystal display (LCD) or a computer monitor with the test result shown as either "pass" or "refer".

\section{Auditory Brainstem Response (ABR)}

The ABR is an electrophysiological response in the Electroencephalograph (EEG) generated by the brainstem in response to auditory signals such as clicks or tones which is painless and noninvasive. The stimulus is delivered via earphones or an inserted ear probe and scalp electrodes are used to pick up the signal. ABR evaluates the integrity of the peripheral auditory system and the auditory nerve pathways up to the brainstem and is able to identify infants who have normal cochlear function but abnormal eighth-nerve function (auditory neuropathy). Detection of wave $\mathrm{V}$ in the ABR measurements is the most reliable objective diagnosis and quantification of hearing loss in children.

\section{ABR Procedure}

The procedure for ABR is done in our centre based on appointment because most of them are sedated and usually starved. The sedation is done by the anaesthetists while the ABR procedure is carried out by the Audiologist in a quiet room. The patient would lie supine on a couch that is specifically meant for the procedure, but may change to the left or right lateral recumbent position for ease of access to each of the mastoids. Infants ABR Procedures are however done under natural sleep after breastfeeding. The procedure lasts between 45 to 60 minutes.

The audiologist attaches adhesive recording electrodes on the forehead and ears, and captures and analyzes recordings of electric potentials generated by the auditory neural pathway. This procedure is performed while the patient is lying down in the sound booth or a quiet room. It is important to remain still and quiet throughout the test, hence the need for sedation most times for children. Small electrodes (sensors that measure brain activity) are placed on the child's forehead and earlobes or mastoid bone, and earphones are placed over his or her ears. An electrode gel is used on the child's head and ears so that there is good contact between the skin and the electrodes. Once the child is sleeping, sound is be played through the earphones. His or her brain's response to this sound, then is recorded through the electrodes and recorded on the computer. The amplitude (micro voltage) of the signal is averaged and charted against the time (millisecond) much like an EEG. The waveform peaks are labeled I - VII. These waveforms normally occur within a 10-millisecond time period after a click stimulus presented at high intensities. 


\section{Demographics}

\section{RESULTS}

There were 52 children studied, 25 (48.1\%) were male while 27 (51.9\%) were female.

Table 1: Age Distribution

\begin{tabular}{lcccccc}
\hline Age in Years & Frequency & Percent & Minimum & Maximum & Mean & Std. Deviation \\
\hline & & & 9 Months & 6 Years & 2.9038 & 1.40391 \\
Below 1 year & 2 & 3.8 & & & & \\
1 year & 7 & 13.5 & & & \\
2 years & 8 & 15.4 & & & \\
3 years & 22 & 42.3 & & & \\
4 years & 5 & 9.6 & & & \\
5 years & 6 & 11.5 & & & \\
6 years & 2 & 3.8 & & & \\
Total & $\mathbf{5 2}$ & $\mathbf{1 0 0 . 0}$ & & & & \\
\hline
\end{tabular}

Table 1 above shows that $2(3.8 \%)$ were below one year old, $7(13.5 \%)$ were a year old and above, 8 (15.4\%) were 2 years old and above, 22 (42.3\%) were 3 years old and above, 5 (9.6\%) were 4 years old and above, $6(11.5 \%)$ were 5 years old and above, $2(3.8 \%)$ were 6 years old and above.

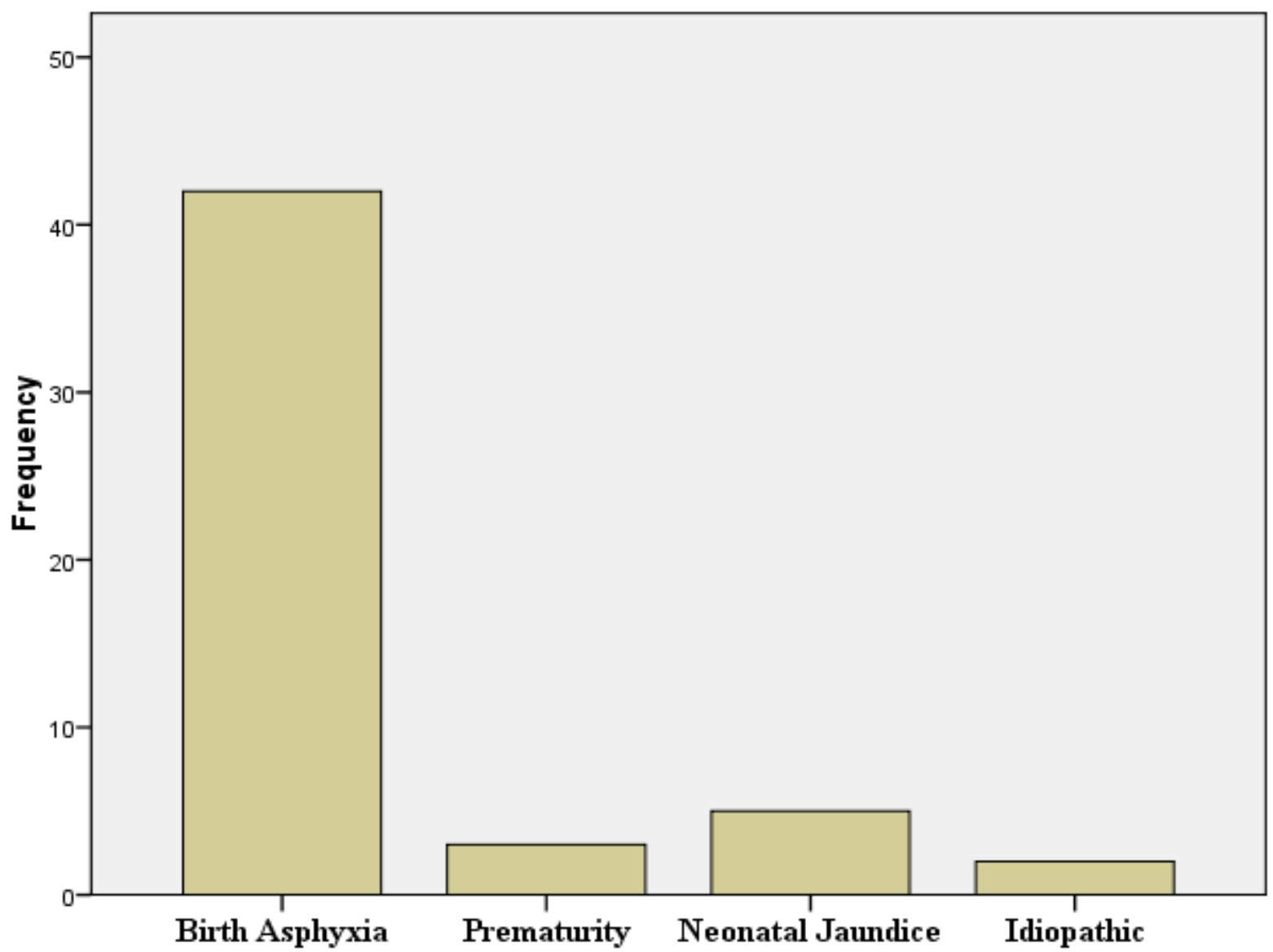

Figure 1: Presumed Causes of Hearing Loss among the Children

Figure 2 above shows the probable causes of hearing loss among the participants in which birth asphyxia is the most prevalent cause with 42 children $(80.8 \%)$ followed by neonatal jaundice with 5 children (9.6\%), prematurity $3(5.8 \%)$ and idiopathic $2(3.8 \%)$. 
Tobih, J. E., Sogebi, O. A., Adeosun, A. A., Olaosun, A. O., Odetoyinbo, O., Adedeji, T. O., Ojurongbe, B. F., Adegbosin, B. A., Adeyemo, Y. I., \& Ogundiran, O. (2019). Electrophysiological Assessment, Causes and Management of Children With Supposed Hearing Loss in a Nigerian Ear Clinic. Advances in Social Sciences Research Journal, 6(9) 213-223.

Table 2: Mode of Sleep Inducement

\begin{tabular}{lcc}
\hline Sleep Inducement & Frequency & Percent \\
\hline Breast-feeding & 9 & 17.3 \\
Drug & 43 & 82.7 \\
Total & 52 & 100.0 \\
\hline
\end{tabular}

The above table 2 shows that $9(17.3 \%)$ were induced through breast feeding while $43(82.7 \%)$ had conscious sedation.

Table 3: Right Ear Otoacoustic Emissions

\begin{tabular}{lcc}
\hline OAE & Frequency & Percent \\
\hline Pass & 7 & 13.5 \\
Refer & 45 & 86.5 \\
Total & 52 & 100.0 \\
\hline
\end{tabular}

Table 3 showing Otoacoustic emissions report on the right ears reveals that only $7(13.5 \%)$ passed while the remaining $45(86.5 \%)$ referred.

Table 4: Left Ear Otoacoustic Emissions

\begin{tabular}{lcc}
\hline OAE & Frequency & Percent \\
\hline Pass & 7 & 13.5 \\
Refer & 45 & 86.5 \\
Total & 52 & 100.0 \\
\hline
\end{tabular}

Table 4 showing Otoacoustic emissions report on the left ears reveals that only 7 (13.5\%) passed while the remaining $45(86.5 \%)$ referred.

Table 5: Right Ear Degrees of Hearing Loss through Auditory Brainstem Response

\begin{tabular}{lcc}
\hline Degree of Hearing & Frequency & Percent \\
\hline Normal Hearing & 6 & 11.5 \\
Mild HL & 5 & 9.6 \\
Moderate HL & 3 & 5.8 \\
Mod Severe HL & 25 & 48.1 \\
Severe HL & 7 & 13.5 \\
Profound HL & 6 & 11.5 \\
Total & $\mathbf{5 2}$ & $\mathbf{1 0 0 . 0}$ \\
\hline
\end{tabular}

Table 6: Left Ear Degrees of Hearing Loss through Auditory Brainstem Response

\begin{tabular}{lcc}
\hline Degree of HL & Frequency & Percent \\
\hline Normal Hearing & 4 & 7.7 \\
Mild HL & 6 & 11.5 \\
Moderate HL & 4 & 7.7 \\
Mod. Severe HL & 24 & 46.2 \\
Severe HL & 8 & 15.4 \\
Profound HL & 6 & 11.5 \\
Total & $\mathbf{5 2}$ & $\mathbf{1 0 0 . 0}$ \\
\hline
\end{tabular}




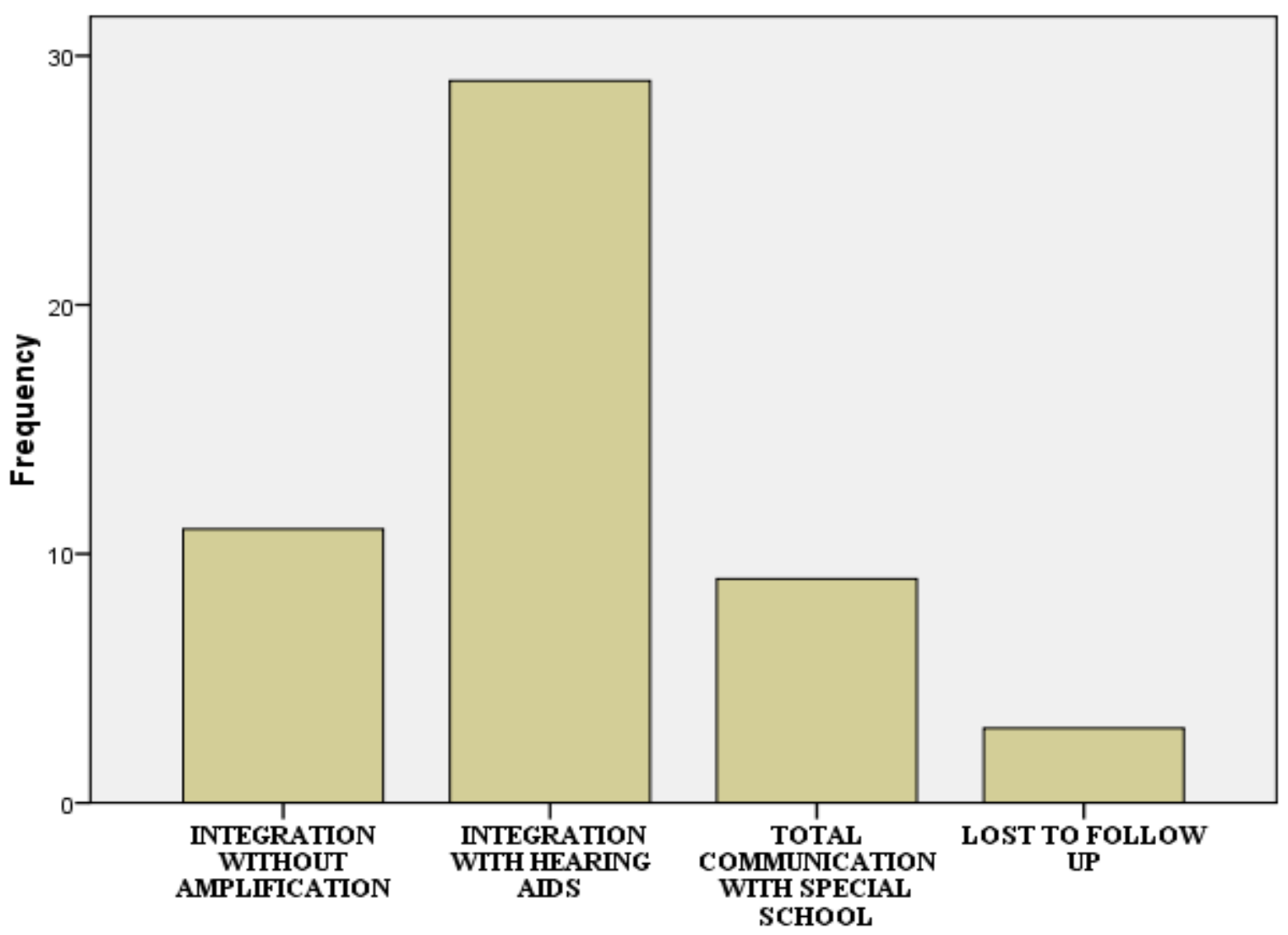

Figure 2: Management (Rehabilitation)

The above figure 2 shows that more than half of the patients, that is, 29 out of 52 patients $(55.8 \%)$ were integrated with hearing aids, 11 (21.2\%) patients were integrated into normal school without amplification, 9 (17.3) patients were enrolled with total communication in special schools while the remaining $3(5.8 \%)$ patients were lost to follow-up.

\section{DISCUSSION}

The Joint Committee on Infant Hearing issued its eighth position statement to endorse the early hearing detection and intervention (EHDI) for infants with hearing loss with the overall goal of maximizing the linguistic competence and literacy development for infants and young children who are deaf or hard of hearing [13]. The 2007 statement continues to follow the "13-6 EHDI Plan" as outlined in the first three of the eight principles presented in the position statement.

Most children with hearing impairment in Nigeria are diagnosed only when speech has failed to develop, partly because of the absence of routine or targeted newborn hearing screening [14] and parents' failure to or delay in recognizing the problem [15]. The JCIH recommends routine hearing screening for all newborn babies, however, for developing nations and remote areas where lack of resources might limit the development of newborn screening programmes, an initial focus on screening of high-risk newborns and Neonatal Intensive Care Unit (NICU) graduates is recommended [2]. Screening in this group is important as the risk of moderate to severe permanent hearing loss is 10-20 times higher than in the general population (16). However, this is hampered by constraints of manpower and availability and/or access to screening modalities and probably non-recognition of the need by the appropriate health authorities, consequently, newborn screening programs are not available in many developing 
Tobih, J. E., Sogebi, O. A., Adeosun, A. A., Olaosun, A. O., Odetoyinbo, O., Adedeji, T. O., Ojurongbe, B. F., Adegbosin, B. A., Adeyemo, Y. I., \& Ogundiran, O. (2019). Electrophysiological Assessment, Causes and Management of Children With Supposed Hearing Loss in a Nigerian Ear Clinic. Advances in Social Sciences Research Journal, 6(9) 213-223.

countries including Nigeria where there is availability of manpower but lack of facilities and health policies are huge drawback.

Findings from this study suggest that majority (86.6\%) of the cases are congenital hearing loss resulted from acquired causes especially birth asphyxia. This figure is significantly higher than those reported in a study by Dunmade et al. [17]. In a similar study from another region of the country, lack of skilled attendants at birth rather than non-hospital delivery by mothers significantly correlated with permanent congenital hearing loss in Nigeria. Thus, the consequent labour and perinatal complications such as prolonged obstructed labour, intrapartum stress, birth asphyxia, pre-eclampsia/eclampsia have significant effects on infants hearing [18].

There is a need to improve upon childhood immunization programs to make available vaccines that are viable and potent, and promote wider and effective coverage and inclusion of those vaccines that have not been incorporated into the scheme. Particular attention should be focused on rubella vaccination for all ladies in the reproductive age group. An effective immunization program against meningococcal meningitis in Gambia has reduced the incidence of congenital hearing loss in the country [19]. Previous similar study in India reported a low percentage of children with rubella-induced hearing impairment and concluded that the low rate may be due to appropriate immunization of mothers to the rubella infection during their child-bearing years [20].

Other factors, for example, certain practices of some non-government hospitals and Traditional Birth Attendants (TBAs), from initial management of labor complications to delay in referral to health facilities, may have placed some children at risk of congenital hearing loss. Mothers who have received antenatal care in hospitals and are trying to avoid possible caesarean section often seek vaginal delivery in non-hospital-based facilities, even when this mode of delivery presents significant risks to both mother and child [21]. Referral to a hospital occurs late and only where there is a glaring failure of vaginal delivery [18]. According to WHO data, the proportion of births without skilled attendants in Nigeria is 64.8\% [22] and a lack of skilled attendants and bad obstetric practices in such settings have been associated with a high prevalence of permanent acquired congenital hearing loss. The majority of the deliveries in our series were at private facilities manned by traditional birth attendants. The need for training and retraining of such personnel should be advocated so that they will know their limitation and appropriate time to refer to prevent the majority of those acquired cases of hearing loss attributable to bad obstetric practices [18].

The high risk and association between neonatal jaundice (NNJ) and congenital hearing loss have been documented [23]. Moreover, the resultant unconjugated hyperbilirubinemia from rapid hemolysis of the red cells has been implicated in the pathogenesis of this condition in Nigeria [24]. The primary prevention of NNJ would necessitate public education on the causes of NNJ, the avoidance of hemolytic agents, particularly at antenatal clinics, and prompt recognition and early presentation of neonates with NNJ. Prompt treatment with phototherapy and exchange blood transfusion is essential for rapid elimination of the dangers from the neurotoxin effects of unconjugated hyperbilirubinemia.

In tables 3 and 4 , it was revealed from OAE reports that $86.5 \%$ of the patients had hearing loss on both ears. ABR results also revealed in tables 6 and 7 that only $11.5 \%$ were normal on the right ears while $7.7 \%$ were normal on the left ears, this means that $88.5 \%$ and $92.3 \%$ had hearing loss on the right and left ears respectively. According to WHO, hearing loss is disabling 
in children aged 0 - 14 years when Pure Tone Average in the better ear is greater than $30 \mathrm{~dB}$. Even those with mild hearing loss, especially those with more than $30 \mathrm{~dB}$ may have some disabling hearing loss and that is the reason different approaches and interventions were given to the affected children according to their degrees of hearing loss [3].

International statistics for children with hearing impairment are reported to be 2-6 / 1000 live-birth. Significant hearing loss is present in 1 to 6 per 1000 newborns [25]. In the United State of America, prevalence of minimal sensorineural hearing loss in school - aged children is $11.3 \%$ [26]. In Nigeria, reports from studies confirmed that the prevalence of hearing loss in school -age population ranges from 6.7 to $8.9 \%$ [27]. Our findings cannot be compared because it is more of case series rather than prevalence

Figure 2 reveals our management of patients with congenital hearing loss, $21.2 \%$ were integrated into normal schools without any form of amplification because many of them were having normal hearing while the remaining were having non-disabling hearing loss (hearing loss not more than $30 \mathrm{~dB}$ ). The main reason for their referral was due to speech delay, however, they were reassured that speech would develop and regular follow-up was done for them. It was also revealed that more than half of the participants (55.8\%) were integrated with hearing aids into normal schools. We do hearing aid assessment for our patients with congenital hearing loss, although majority of them presented late but the outcomes of hearing aid assessment were beneficial, thus we recommended hearing aid fitting, some were fitted with binaural hearing aids while some were fitted with monaural. Finance is a big constraint for parents of these children needing hearing aids, many of the parents were unable to purchase for their children with unilateral hearing loss, let alone those with bilateral hearing loss. What parents did was to purchase hearing aid only for one ear even though the child might have had bilateral hearing loss, thus, it was fitted into the better ear. However, a few parents were able to afford binaural hearing aid fitting for their children and this made it possible for these children to fit in and cope with their hearing counterparts in the regular schools.

The remaining percentage $(17.3 \%)$ of the patients we managed was referred to special schools and these children were enrolled with total communication in special schools. Special education (also known as special-needs education, aided education or exceptional education) is the practice of educating pupils / students in a way that addresses their individual differences and needs. Ideally, this process involves individually planned and systematically monitored arrangement of teaching procedures, adapted equipment and materials, and accessible settings. These interventions are designed to help individuals with special needs achieve a higher level of personal self-sufficiency and success in school and in their community, which may not be available if the students were only given access to a typical classroom education and environment. These $17.3 \%$ were patients with severe to profound hearing loss, although some could have been placed in a regular school if they could afford hearing aids or cochlear implants and would develop speech and language with these technological advancement but due to financial constraint, their parents abandoned them to their fate and unfortunately there is no government policy towards this category of children.

It is noteworthy to say that some of our patients with severe to profound hearing loss were placed in special schools to start communicating with total communication (sign language and oral communication) some (5.8\%) were lost to follow up. This may be attributed to financial constraints too and patients hope being dashed, even with proper counseling that the prognosis is high if they can take advantage of technological advancement and special education; no matter what parents are told or the extent to which they are counseled, their 
Tobih, J. E., Sogebi, O. A., Adeosun, A. A., Olaosun, A. O., Odetoyinbo, O., Adedeji, T. O., Ojurongbe, B. F., Adegbosin, B. A., Adeyemo, Y. I., \& Ogundiran, O. (2019). Electrophysiological Assessment, Causes and Management of Children With Supposed Hearing Loss in a Nigerian Ear Clinic. Advances in Social Sciences Research Journal, 6(9) 213-223.

minds are usually made up and that may just be the last time they visit the clinic. Unfortunately, government is not helping with these issues, augmentation of hearing especially for children with hearing loss should not be shouldered solely by their parents.

\section{CONCLUSION}

Early identification of hearing loss followed by prompt and suitable interventions can go a long way in helping to ensure that children with pre-lingual hearing loss enjoy equal opportunities in the society like their hearing counterparts. There is, therefore, an urgent need to identify infants and children with hearing loss as promptly as possible so that appropriate interventions can be instituted. This study has thus assisted in elucidating the audiological characteristics and mode of rehabilitation of children with congenital and pre-lingual hearing loss in a developing country.

\section{Reference:}

American Academy of Pediatrics; Joint Committee on Infant Hearing. Year 2007 position statement: principles and guidelines for early hearing detection and intervention programs. Pediatrics, 2007; 120: 898-921.

Global estimates on the prevalence of hearing loss. World Health Organisation, 2012 [cited 14th January 2017].

WHO 2018. 10 Facts about deafness. https://www.who.int/features/factfiles/deafness/en/ retrieved 14th February, 2019.

Olusanya BO, Newton VE. Global burden of childhood hearing impairment and disease control priorities for developing countries. Lancet, 2007;369:1314-1317.

Swanepoel D, Störbeck C, Friedland P. Early hearing detection and intervention in South Africa. Int J PediatrOtorhinolaryngol, 2009;73:783-790

Jamison DT, Breman JG, Measham AR. Disease control priorities in developing countries. 2nd ed. New York, NY: Oxford University Press; 2006.

Lieu JE . Speech-language and educational consequences of unilateral hearing loss in children. Arch Otolaryngol Head Neck Surg, 2004;130:524-530

Allen,TE . Patterns of academic achievement among hearing impaired students: 1974 and 1983. In: Schildroth, AN, Karchmer, MA eds. Deaf Children in America. Boston, MA: College-Hill Press; 1986:161-206.

Holden-Pitt L, Albertori J. Thirty years of the annual survey of deaf and hard-of-hearing children and youth: a glance over the decades. Am Ann Deaf, 1998;143:72-76.

Mohr PE, Feldman JJ, Dunbar JL. The societal costs of severe to profound hearing loss in the United States. Int J Technol Assess Health Care, 2000;16:1120-1135.

Roux le, Swanepoel de T, Louw W, Vinck A, Tshifularo B. Profound childhood hearing loss in a South Africa cohort: risk profile, diagnosis and age of intervention. Int J Pediatr Otorhinolaryngol, 2015;79:8-14

American Academy of Audiology. Childhood hearing screening guidelines.

https://www.cdc.gov/ncbddd/hearingloss/documents/aaa_childhood-hearing-guidelines_2011.pdf. Published September 2011. Accessed January 22, 2017.

Committee on Infant Hearing. Year 2007 position statement of the Joint Committee on Infant Hearing: Principles and guidelines for early hearing detection and intervention programs. Pediatrics,2007; 120: 898-921.

Olusanya B, Ebuehi O, Somefun A. Universal infant hearing screening programme in a community with predominantly non-hospital births: a three-year experience. J Epidemiol Commun Health 2009; 63:481-6.

Ijaduola G. The problems of the profoundly deaf Nigerian child. Postgr Doctor Afr ,1982; 4:180-4.

Nelson HD, Bougatsos C, Nygren P. Universal newborn hearing screening: systematic review to update the 2001 US preventive services task force recommendation. Pediatrics, 2008; 122:266-76.

Dunmade AD, Segun-Busari S, Olajide TG, Ologe FE. Profound bilateral sensorineural hearing loss in nigerian children: any shift in etiology? J Deaf Stud Deaf Educ 2007;12:112-118. 
Olusanya BO, Wirz SL, Luxon LM. Non-hospital delivery and permanent congenital and early-onset hearing loss in a developing country. BJOG, 2008;115:1419-1427.

Dietz A, Löppönen T, Valtonen H, Hyvärinen A, Löppönen H. Prevalence and etiology of con ᄀgenital or early acquired hearing impairment in Eastern Finland. Int J Pediatr Otorhinolaryngol, 2009;73:1353-1357.

Wild NJ, Sheppard S, Smithells RW, Holzel H, Jones G. Onset and severity of hearing loss due to congenital rubella infection. Arch Dis Child, 1989;64:1280-1283.

Filippi V, Ronsmans C, Campbell OM, Graham WJ, Mills A, Borghi J, et al. Maternal health in poor countries: the broader context and a call for action. Lancet, 2006; 368:1535-1541.

Fzechi OC, Fasubaa OB, Obiesie LO, Kalu BK, Loto OM, Dubub VI, et al. Delivery outside hos $\neg$ pital after antenatal care: prevalence and its predic ᄀtors. J Obstet Gynaecol, 2004; 24:745-749.

Bullough C, Meda N, Makowiecka K, Ronsmans C, Achadi EL, Hussein J. Currentstrategies for the reduction of maternal mortality. BJOG, 2005; 112:1180-1188.

Attias J, Al-Masri M, Abukader L, Cohen G, Merlov P, Pratt H, et al. The prevalence of congenital and early-onset hearing loss in Jordanian and Israeli in $\neg$ fants. Int J Audiol, 2006; 45:528-536.

Bachmann KR, J.C. Arvedson JC. Early Identification and Intervention for Children Who are Hearing Impaired. Pediatr. Rev,1998; 19: 155-165.

Bess F.H., Dodd-MurphyJ, ParkerRA. Children with minimal sensorineural prevalence, educational performance and functional status. Ear and Hearing,1998. 19: 339-54.

Olusanya BO, Okolo AA, Ijaduola GTA. The hearing profile of Nigerian school children. Int J. Pediatr Otorhinolaryngol.,2000; 55: 173-179. 